Jurnal Kebidanan 10 (01) 1 - 102

Jurnal Kebidanan

http : //www. journal.stikeseub.ac.id

\title{
KEPUASAN PASIEN PADA PELAYANAN BIDAN DI POSKESDES
}

\author{
Allania Hanung ${ }^{1)}$ Tinah $^{2)}$ Ayu Rosita Fidianata ${ }^{3)}$ \\ 1), 2), 3) Program Studi D III kebidanan, STIKES Estu Utomo Boyolali \\ E-mail: allaniahanung@gmail.com
}

\begin{abstract}
ABSTRAK
Pelayanan kebidanan adalah bagian integral dari sistem pelayanan kesehatan yang diberikan oleh bidan yang telah terdaftar (teregistrasi) yang dapat dilakukan secara mandiri, kolaborasi atau rujukan. Pelayanan kesehatan yang bermutu semakin diperlukan dalam memenuhi tuntutan kebutuhan masyarakat. Bidan memang harus memuaskan pelanggan, sebab kalau pelanggan tidak dipuas pelanggan akan meninggalkan dan menjadi pelanggan pesaing untuk mendapatkan pelayanan yang diharapkan, hal ini akan menurunkan laba dan bahkan menimbulkan kerugian. Oleh karena itu, bidan desa diharapkan untuk selalu konsisten pada perannya, terutama kuantitas dan kualitas pelayanan dalam upaya memuaskan kebutuhan dan keinginan pasien. Tujuan Penelitian : Untuk mengetahui kepuasan pasien KIA yang kunjungan ke bidan di desa pucangan. Metode penelitian : Penelitian yang dilakukan dengan analitik observasional dengan menggunakan pendekatan cross sectional. Populasi dalam penelitian ini adalah adalah pasien KIA yamg memeriksakan diri diBidan Desa Pucangan dengan 34 pasien KIA, dengan teknik sampling aksidental dan analisa data dengan Kuesioner. Hasil Penelitian : Responden yang paling banyak adalah responden yang melakukan kunjungan tetap dengan kepuasan pelayanan bidan cukup yaitu 22 responden $(64,7 \%)$, Hasil perhitungan chi square dengan $\alpha=0,05$, diperoleh nilai p value 0.000 $<0.005$, berarti Ha diterima dan Ho ditolak. Kesimpulan : Dari penelitian ini dapat disimpulkan bahwa ada hubungan kepuasan pelayanan bidan desa dengan kunjungan pasien KIA.
\end{abstract}

Kata Kunci : Kepuasan, pelayanan, bidan

\section{PATIENT SATISFACTION AT MIDWIFE SERVICES AT POSKESDES}

\section{ABSTRACT}

Background: midwifery Services are an integral part of the system of health services provided by the registered midwife (registered) can be done independently, collaboration or referral. Quality health care is increasingly necessary in meeting the demands of the needs of the community. Midwives did have to satisfy customers, because if the customer is not dipuas customers would leave and become a customer of a competitor to get a service that is expected, it will lower profits and even losses. Therefore, the village midwife is expected to always be consistent on its role, particularly the quantity and quality of service in an effort to satisfy the needs and wishes of the patient. Research objectives: to know the patient's satisfaction KIA is a visit to a midwife in the village of pucangan. Research methods: research conducted with observational analytic approach with the use of cross sectional. The population in this research is the patient checked himself in to KIA'S midwives, Village Pucangan with 34 patients with KIA, aksidental sampling and analysis data by questionnaire. Research results: Respondents most respondents that do visit are fixed to the satisfaction of enough midwives services 22 respondents $(64,7 \%)$, the results of the calculation of the chi square with $\alpha=0.05$, the $p$ value obtained value $0000 \quad 0,005$, meaning $<\mathrm{HaHo}$ accepted and rejected. Conclusion: From this research it can be concluded that there is a relationship of service satisfaction with patient visits the village midwife KIA

Keywords: patient, satisfaction, midwife 


\section{PENDAHULUAN}

Pelayanan kebidanan adalah bagian integral dari sistem pelayanan kesehatan yang diberikan oleh bidan yang telah terdaftar (teregistrasi) yang dapat dilakukan secara mandiri, kolaborasi atau rujukan (Keputusan Menteri Kesehatan Republik Indonesia Nomor 369 / MENKES / SK/ III /2007). Peran aktif bidan dalam Kesehatan Ibu Dan Anak sudah sangat diakui oleh semua pihak. Seiringnya perkembangan ilmu pengetahuan, sosial dan ekonomi pada masa kini dan masa depan menunjukkan bahwa masyarakat semakin menyadari perlunya meningkatkan dan mempertahankan kualitas hidup (quality of life) di masyarakat sehingga semakin maju tingkat pendidikan yang kemudian membuat masyarakat dapat memberikan penilaian terhadap kualitas pemenuhan kebutuhan. Begitu kompleksnya masalah kehidupan sekarang ini menyebabkan masalah kesehatan benar-benar merupakan kebutuhan penting.

$$
\text { Pelayanan kesehatan yang }
$$

bermutu semakin diperlukan dalam memenuhi tuntutan kebutuhan masyarakat. Untuk memenangkan persaingan yang semakin ketat tersebut, bidan harus mampu memberikan kepuasan terhadap pelanggan dalam hal ini adalah pasien. Berbagai penelitian menunjukkan bahwa $66 \%$ persalinan,
93\% kunjungan antenatal (KIA), $80 \%$ dari pelayanan keluarga berencana dilakukan oleh bidan. Angka kunjungan merupakan tolak ukur kesukses suatu bidan desa dalam menilai efektivitas dan efisiensi pelayananan yang diberikan apakah sesuai dengan harapan pasien atau belum.

Berkaitan dengan pelayanan yang bermutu atau berkualitas yang dihubungkan dengan kepuasan, maka menurut Zeithaml dan M.T.Bitner dan Adrian Palmer (2001) yang dikutip Sari ada lima faktor yang mempengaruhi mutu pelayanan yaitu keandalan (reliability), ketanggapan (responsivenes), jaminan (assurance), empati (empathy) dan keberwujudan (tangibles)(Sari, 2008). Kelima hal tersebut adalah penentu kepuasa klien pada pelayanan bidan. Kepuasan didapatkan dari membandingkan ekspektasi dan harapan terhadap kenyataan yang klien dapatkan (Supranto, 2006).

Oleh karena itu, perusahaan jasa kesehatan, diantaranya adalah bidan desa, diharapkan untuk selalu konsisten pada perannya, terutama kuantitas dan kualitas pelayanan dalam upaya memuaskan kebutuhan dan keinginan pasien. Selanjutnya pihak manajemen segera melakukan evaluasi terhadap kinerja. 
Studi pendahuluan yang dilakukan peneliti dengan melakukan rekap laporan per bulan Kunjungan Kesehatan Ibu dan Anak (KIA) di Bidan Desa Pucangan pada bulan Januari tahun 2017 kunjungan pasien KIA sebanyak 108. Pada bulan Februari tahun 2017 mengalami penurunan menjadi 88 pasien KIA. Pada 2 bulan terakhir pasien mengalami penurunan menjadi 73 pasien KIA. Pasien yang datang ke Bidan Desa meliputi hamil, kontrol nifas, KB, imunisasi.

\section{Kepuasan Pasien}

Kepuasan pasien saat ini menjadi tolak ukur keberhasilan dalam memberikan pelayanan kesehatan. Walaupun sebenarnya, kepuasan pasien belum tentu dapat menggambarkan sepenuhnya kompetensi tenaga kesehatan. (González et al., 2005) Kepuasan pasien merupakan suatu hasil dari sikap pemberi layanan kesehatan serta kemampuan pengetahuan yang dievaluasi menggunakan respon emosional pasien. (Wilson et al., 2006) Saat ini, harapan pasien terhadap pelayanan medis semakin meningkat sehingga menyebabkan tuntutan pelayanan medis yang lebih baik. (Ware, Devies - Avery dan Stjohn wareewart).

Penilaian kepuasan pasien terhadap karakteristik tenaga kesehatan dan pelayanan kesehatan digunakan untuk menilai program kesehatan yang sedang berjalan, termasuk didalamnya program pendidikan kesehatan (Ware dan Snyder, 1975). Kepuasan adalah sikap klien yang disebabkan oleh hasil, pelayanan, atau proses. Sikap yang dimaksud disini adalah yang terukur lebih menyeluruh terhadap hasil dan pelayanan. (Parasuraman, Zeithaml dan Berry, 1988).

Menurut Kotler \& Amstrong dalam Huriyati dan Rangkuti faktorfaktor yang mempengaruhi kepuasan berhubungan dengan tingkah laku konsumen yaitu faktor budaya, faktor sosial, faktor pribadi dan faktor psikologi (Rangkuti, 1997; Huriyati, 2005). Kepuasan pasien dipengaruhi oleh banyak faktor, antara lain : pendekatan dan perilaku petugas, perasaan klien terutama saat pertama kali datang, mutu informasi yang diterima, outcomes pengobatan dan perawatan yang diterima, prosedur perjanjian, waktu tunggu. Oleh karena itu, kepuasan pasien merupakan respon kebutuhan pasien terhadap keistimewaan suatu kualitas produk jasa atau pelayanan.

Ada lima faktor yang mempengaruhi mutu pelayanan yaitu : 1. Keandalan (reliability) Kemampuan petugas memberikan pelayanan dengan segera, tepat waktu dan benar misalnya penerimaan yang cepat, pelayanan 
pemeriksaan dan perawatan yang cepat dan tepat. Kehandalan juga merupakan kemampuan bidan dalam pelayanan yang akurat atau tidak ada kesalahan : 2. Ketanggapan (responsivenes) Kemampuan petugas dalam menanggapi keluhan pasien termasuk kemampuan petugas untuk cepat tanggap dalam menyelesaikan keluhan dan tindakan cepat pada saat dibutuhkan ;

3. Jaminan (assurance) Kepercayaan pasien terhadap jaminan kesembuhan dan keamanan sehingga akibat pelayanan yang diberikan termasuk pengetahuan termasuk pengetahuan petugas kesehatan dalam memberikan tindakan pelayanan nifas. Aspek ini juga mencakup kesopanan dan sifat dapat dipercaya yang dimiliki oleh petugas, bebas dari bahaya, resiko, keragu raguan; 4. Empati (empathy) Kemudahan dalam melakukan hubungan komunikasi yang baik dan memahami kebutuhan klien yang terwujud dalam penuh perhatian terhadap setiap pasien; 1. Keberwuju (tangibles) Fasilitas fisik, peralatan dan penampilan petugas, kebersihan, kerapian dan kenyamanan ruangan, kesiapan dan kebersihan alat. Pasien akan menggunakan indra penglihatan untuk menilai kualitas pelayanan seperti menilai gedung, peralatan, seragam, yaitu hal - hal yang menimbulkan kenikmatan bila dilihat.

\section{Kunjungan}

Pengertian Kunjungan Pasien adalah pemanfaatan penggunaan fasilitas kesehatan yang disediakan baik dalam bentuk rawat jalan, rawat inap, kunjungan rumah oleh petugas kesehatan maupun dalam bentuk kegiatan lain dari pemanfaatan pelayanan kesehatan tersebut. Tingkat kunjungan ulang dalam jasa pelayanan kesehatan di tunjukan dengan perilaku kunjungan pasien ke unit pelayanan kesehatan sebagai tingkat kepuasan sebagai tingkat kepuasan pasien terhadap penyelenggaraan pelayanan kesehatan. Kunjungan juga berarti adanya kepercayaan pasien terhadap organisasi penyelenggara pelayanan kesehatan untuk memenuhi kebutuhannya. Besarnya tingkat kunjungan pasien ke fasilitas pelayanan kesehatan dapat dilhat dari dimensi waktu yaitu harian, mingguan, bulanan dan tahunan.

Untuk mengukur terpenuhi atau tidaknya suatu standar kualitas pelayanan kesehatan yang telah ditetapkan, dipergunakan indikator yang merupakan fenomena yang menunjukan pada kewajaran dan derajat kualitas pelayanan kesehatan yang diberikan. Indikator ini mengacu pada bebagai aspek kualitas yaitu aspek klinis atau penampilan profesi, aspek efektif dan 
efisien, aspek keselamatan pasien dan aspek kepuasan pasien. Keberhasilan suatu pelayanan kesehatan, harus dilaksanakan dalam waktu dan cara yang tepat, oleh pemberi layanan yang tepat dan menggunakan peralatan dan obat yang tepat sert dengan biaya yang efisien.

\section{Pelayanan Bidan}

Pelayanan kebidanan adalah seluruh tugas yang menjadi tanggung jawab profesi bidan dalam sistem pelayanan kesehatan yang bertujuan untuk meningkatkan kesehatan kaum perempuan khususnya ibu dan anak - anak. Pelayanan kebidanan yang tepat akan meningkatan keamanan dan kesejahteraan ibu dan bayinya. Layanan kebidanan oleh bidan dapat dibedakan meliputi :

1. Layanan kebidanan primer yaitu layanan yang diberikan sepenuhnya atas tanggung jawab bidan.

2. Layanan kolaborasi yaitu layanan yang dilakukan oleh bidan sebagai anggota tim secara bersama-sama dengan profesi lain dalam rangka pemberian pelayanan kesehatan.

3. Layanan kebidanan rujukan yaitu merupakan pengalihan tanggung jwab layanan oleh bidan kepada sistem layanan yang lebih tinggi atau yang lebih kompeten ataupun pengambil alihan tanggung jawab layanan/menerima rujukan dari penolong persalinan lainnya seperti rujukan.

\section{METODE}

Studi ini menggunakan desain penelitian analitik observasional dengan menggunakan pendekatan cross sectional. Variabel bebas pada studi ini adalah kepuasan pasien terhadap pelayanan bidan. Sedangkan variabel terikat dalam penelitian ini adalah kunjungn pasien KIA.

Populasi dalam studi ini adalah pasien KIA yang memeriksakan diri di Bidan Desa Pucangan dengan sebanyak 34 pasien KIA pada bulan Mei. Pengambilan sampel dalam penelitian secara total sampling dimana semua pasien KIA yang memperiksakan dijadikan sampel. Studi dilakukan pada bulan Mei 2017 di Desa Pucangan.

Instrumen yang digunakan untuk mengukur kepuasan pasien adalah kuesioner yang telah diuji validitas dan reliabilitasnya sebanyak 19 item pertanyaan. Sedangkan untuk menilai kunjungan KIA menggunakan buku KIA pasien.

Metode pengumpulan data variabel kepuasan pasien menggunakan data primer dari hasil kuesioner kepuasan pasien. Sedangkan untuk variabel kunjungan KIA menggunakan data sekunder dari buku KIA pasien. 
Teknik analisa data pada penelitian ini menggunakan analisa univariat dan analisa bivariat. Analisa bivariat dalam penelitian ini menggunakan analisa chi square dengan taraf signifikansi 0,05 .

\section{HASIL DAN PEMBAHASAN}

\section{Hasil}

Hasil dari penelitian ini bahwa desa Pucangan terletak di Kartasura tepantya masuk dalam wilayah kecamatan Kartasura. Bidan Desa Pucangan bertempat tiggal di pos kesehatan desa yang berada ditengah desa Pucangan. Desa pucangan merupakan desa yang berlokasi strategis karena berada dipinggir kota Kartasura. Dimana memiliki batas wilayah sebelah Barat desa Bolon, Timur desa Sanggrahan, Utara desa Singopuran, Selatan desa Sawit. Di Bidan desa melayani kunjungaan KIA dan umum. Dengan seorang tenaga medis yaitu seorang bidan desa.
Tabel 1. Karakteristik Responden Berdasarkan Kunjungan KIA di Desa Pucangan Mei 2017

\begin{tabular}{lcc}
\hline Kunjungan & Frekuensi & $\begin{array}{c}\text { Prosentase } \\
(\%)\end{array}$ \\
\hline Kunjungan awal & 6 & 17,6 \\
Kunjungan ulang & 28 & 82,4 \\
\hline Jumlah & 34 & 100 \\
\hline Sumber: Data Primer, Tahun 2017 &
\end{tabular}

Berdasarkan Tabel 1 diatas dari 34 responden dapat diketahui bahwa responden terbanyak yaitu kunjungan ulang sebanyak 28 responden $(82,4 \%)$.

\section{Tingkat Kepuasan Pelayanan Bidan}

Tabel 2. Karakteristik Responden Berdasarkan Kepuasan Pelayanan Bidan Desa di Desa Pucangan Mei 2017

\begin{tabular}{lcc}
\hline $\begin{array}{l}\text { Kepuasan } \\
\text { Pelayanan }\end{array}$ & $\begin{array}{c}\text { Freku } \\
\text { ensi }\end{array}$ & $\begin{array}{c}\text { Prosentase } \\
(\%)\end{array}$ \\
\hline Baik & 6 & 17,6 \\
Cukup & 26 & 76,5 \\
Kurang & 2 & 5,9 \\
\hline \multicolumn{1}{c}{ Jumlah } & 34 & 100 \\
\hline
\end{tabular}

Sumber: Data Primer, Tahun 2017

Berdasarkan Tabel 2 diatas dari 34 responden dapat diketahui bahwa kepuasan pelayanan responden terbanyak yaitu cukup sebanyak 26 responden $(76,5 \%)$.

Hubungan antara Hubungan Kepuasan Pelayanan Bidan Desa dengan Kunjungan Pasien KIA di Desa Pucangan.

Tabel 3. Cross Tabulation dan Rangkuman Uji Hubungan Kepuasan Pelayanan Bidan Desa Dengan Kunjungan Pasien KIA

\begin{tabular}{ccccccc}
\hline \multirow{2}{*}{$\begin{array}{c}\text { Kunjungan } \\
\text { KIA }\end{array}$} & \multicolumn{2}{c}{ Kepuasan Pelayanan Bidan Desa } & Total & $P_{\text {value }}$ & $\mathbf{X}^{2}$ \\
\cline { 2 - 4 } & Baik & Cukup & Kurang & & & \\
\hline Awal & - & $4(11,8 \%)$ & $2(5,9 \%)$ & $6(17,6 \%)$ & 0.005 & 10.711 \\
Tetap & $6(17,6 \%)$ & $22(64,7 \%)$ & - & $28(82,4 \%)$ & & \\
\cline { 1 - 5 } Total & $6(17,6 \%)$ & $26(76,5 \%)$ & $2(5,9 \%)$ & $34(100 \%)$ & & \\
\hline
\end{tabular}

Sumber : Data primer yang diolah, Tahun 2017 
Dari tabel 3 tersebut dapat diketahui bahwa responden yang paling banyak adalah responden yang melakukan kunjungan tetap dengan kepuasan pelayanan bidan cukup yaitu 22 responden $(64,7 \%)$, sedangkan yang paling sedikit yaitu responden yang melakukan kunjungan awal dengan kepuasan pelayanan bidan kurang yaitu 2 responden $(5,9 \%)$. Dari hasil uji chi square yang telah di lakukan didapatkan hasil $X^{2} 10,711 \geq 3,219$ dengan $p$ value $0,005<0,05$ berarti $H_{0}$ ditolak yang artinya ada hubungan antara kepuasan pelayanan bidan desa dengan kunjungan ulang KIA dengan keeratan yang cukup yaitu sebanyak $48,9 \%$.

\section{PEMBAHASAN}

\section{Kunjungan Ulang}

Berdasarkan tabel 1 menunjukkan ibu yang melakukan kunjungan ulang sebanyak 28 responden $(82,4 \%)$, sedangkan yang melakukan kunjungan awal yaitu 6 responden (17,6\%). Menurut pasien yang melakukan kunjungan ulang di bidan tersebut bidan memberikan pelayanan dengan sangat ramah dan baik sehingga para responden menyukai bidan tersebut dan akhirnya mereka selalu datang jika sakit maupun sekedar periksa.

Dalam penelitian ini juga terdapat 6 responden $(17,6 \%)$ yang melakukan kunjungan awal, menurut para responden yang melakukan kunjungan awal responden berkunjung ke tempat bidan karena mendapat informasi dari saudara serta tetangga mereka bahwa bidan tersebut memberikan pelayanan yang baik dan ramah sehingga mereka tertarik untuk berkunjung ke tempat bidan tersebut.

Hal ini disebabkan bahwa kepuasan pasien merupakan ujung tombak dalam era persaingan saat ini. Pasien yang puas akan membuat mereka setia untuk tetap menggunakan jasa yang diberikan. Pasien yang loyal akan membuat institusi pemberi jasa mampu bertahan (Prastiwi dan Ayubi, 2008) Persepsi tentang mutu yang buruk akan sangat mempengaruhi keputusan dalam kunjungan berikutnya dan pasien biasanya akan mencari bidan lain. Mutu pelayanan kesehatan disebutkan faktor yang menentukan kualitas jasa pelayanan, yaitu kemampuan, keterampilan dan pengetahuan yang dimiliki petugas harus sesuai dengan pemberi pelayanan.

\section{Kepuasan Pasien}

Tabel 2 menunjukkan bahwa tingkat kepuasan pelayanan bidan desa adalah cukup yaitu 26 responden (76,5\%) hal ini dikarenakan menurut para responden pelayanan yang diberikan oleh bidan desa itu cukup memuaskan selain itu bidannya ramah dan santun terhadap para pelangganya. 
Hal ini disebabkan karena pelayanan yang diberikan bidan sudah cukup baik, sehingga responden merasa puas dan tetep menggunakan jasa yang diberikan bidan. Kepuasan pelayanan yang cukup juga dikarenakan Bidan di desa Pucangan merupakan bidan milik pemerintah, sehingga mutu pelayanan meliputi sarana dan prasarana belum maksimal. (Prastiwi dan Ayubi, 2008)

Hasil penelitian ini sesuai dengan penelitian yang sudah dilakukan oleh Nurjanah bahwa kualitas pelayanan merupakan tingkat kesempurnaan untuk memenuhi keinginan konsumen. Kepuasan berupa perasaan senang atau kecewa seseorang yang dialami setelah membandingkan antara persepsi kinerja atau hasil suatu produk dengan harapan (Nurjanah, 2012). Sedangkan berdasarkan Koesno, hasil studi ini menunjukkan bahwa kualitas pelayanan di Bidan sudah baik. Pelayanan yang ada dan diberikan oleh bidan sudah terstandar secara baku sesuai dengan standar yang ada pada Departemen Kesehatan RI. Standart tersebut telah dituangkan dalam instrument - instrumen Bidan. Pelayanan yang berkualitas tinggi akan menghasilkan reputasi baik bagi bidan sehingga mendorong bidan untuk meningkatkan kinerja. Pelayanan yang berkualitas juga akan memberikan kepuasan kepada pasien yang menerima pelayanan tersebut.
Hubungan antara Tingkat Kepuasan Pelayanan Bidan Desa dengan Kunjungan Ulang

Berdasarkan hasil uji chi-square yang telah dilakukan diperoleh nilai $10,711 \geq 3,219$ dengan $p$ value 0,005 tingkat kesalahan 5\%, maka disimpulkan ada hubungan yang signifikan antara tingkat kepuasan pelayanan bidan dengan kunjungan ulang. Artinya semakin baik kepuasan pelayanan bidan desa kepada pasiennya dapat meningkatkan loyalitas pada bidan tersebut sehingga pasien dengan suka rela melakukan kunjungan ulang pada bidan tersebut.

Dari hasil penelitian kunjungan awal kepuasan cukup 4 orang $(11,8 \%)$. Karena pelayanan bidan kurang baik dan kurang memuaskan. Kunjungan awal kepuasan kurang 2 orang $(5,9 \%)$, ini dikarenakan pelanggan tidak merasa diperhatikan oleh bidan. Konsumen yang menjadi puas dan loyal terhadap suatu jasa tertentu disebabkan oleh kulitas jasa yang baik dan memuaskan. Jika kualitas jasa yang diberikan baik dan memuaskan serta dapat memberikan keuntungan yang maksimal bagi konsumennya maka konsumen pun akan merasa loyal dan memberikan sikap positif kepada penyedia jasa tersebut secara konsisten (Tjiptono, 2008).

Kunjungan tetap kepuasan baik sebanyak 6 orang $(17,6 \%)$, karena mereka sudah percaya dengan bidan dan 
merasa sudah biasa dengan bidannya. Kunjungan tetap cukup sebanyak 26 orang $(16,5 \%)$. Ini dikarenakan mereka sudah lama berkunjung kebidan dan sudah kenal tetapi menurut mereka pelayanannya masih sebatas cukup baik karena tidak sering berkunjung. Dengan terciptanya kepuasan pasien maka akan memberikan banyak manfaat bagi kedua belah pihak antara lain membina hubungan yang harmonis antara pasien dengan bidan, memberikan dasar kunjungan ulang dan terciptanya konsumen yang loyal, serta membentuk komunikasi dari mulut ke mulut (word of mouth). Apabila kualitas jasa yang diterima oleh konsumen lebih baik atau sama dengan yang konsumen bayangkan, maka konsumen cenderung akan puas dan mencobanya lagi (Kotler, 2007). Peningkatan kualitas jasa yang dilakukan secara berkelanjutan oleh bidan desa akan menimbulkan kepuasan dan loyalitas dari pasiennya sehingga terjalin ikatan yang kuat. Dalam jangka ikatan seperti ini dapat membuat bidan desa untuk lebih memahami lebih seksama harapan pasien.

\section{PENUTUP}

Berdasarkan hasil studi mengenai hubungan tingkat kepuasan pelayanan bidan desa dengan kunjungan ulang dapat ditarik simpulan, sebagian besar pasien
KIA memiliki tingkat kepuasan pelayanan bidan desa pucangan pada kategori cukup memuaskan sebanyak 26 responden $(76,5 \%)$, hal ini dikarenakan masih minimnya sarana dan prasarana yang dimiliki oleh bidan desa; Kunjungan terhadap pasien KIA di desa Pucangan melakukan kunjungan tetap ke bidan desa sebanyak 22 responden (64,7\%), hal ini dikarenakan bidan desa tersebut merupakan salah satu tenaga kesehatan terdekat meskipun kepuasan pelayanan yang diberikan belum maksimal; Ada hubungan antara tingkat kepuasan pelayanan bidan desa dengan kunjungan ulang di desa Pucangan.

Mengingat kualitas pelayanan yang diberikan oleh bidan belum maksimal, sebaiknya bidan lebih meningkatkan kualitas yang diberikan dengan cara meningkatkan ketrampilan dan pengetahuan, sopan dan keramahan (sikap), hubungan interpersonal, dan menjalin hubungan baik dengan masyarakat dan menambah sarana dan prasarana.

Sebaiknya tenaga kesehatan khususnya bidan di desa tersebut diharapkan dapat memberikan sosialisasi mengenai pentingnya KIA bagi masyarakat karena KIA dapat memperbaiki sistem kesehatan dalam menerapkan manajemen pelayanan yang lebih efektif. 


\section{DAFTAR PUSTAKA}

González, N. et al. (2005) "Development and validation of an in-patient satisfaction questionnaire," 17(6), hal. 465-472.

Huriyati, R. (2005) Bauran Pemasaran dan Loyalitas Konsumen. Bandung: Alfabeta.

Kotler, P. (2007) Manajemen Pemasaran, Jilid 2. 12 ed. New Jersey: PT Indeks.

Nurjanah, S. (2012) Pengaruh Pelayanan Bidan Delima Terhadap Kepuasan Klien Di Wilayah Kecamatan Banyumanik Kota Semarang. Muhammadiyah Semarang.

Parasuraman, A., Zeithaml, V. dan Berry, L. (1988) "Servqual: A MultipleItem Scale for Measuring Consumer Perceptions of Service Quality," Journal of Retailing, 64(1).

Prastiwi, E. dan Ayubi, D. (2008) "Hubungan Kepuasan Pasien Bayar dengan Minat Kunjungan Ulang di Puskesmas Wisma Jaya Kota Bekasi Tahun 2007.," Makara kesehatan, 12(1).

Rangkuti, F. (1997) Riset Pemasaran. Jakarta: Gramedia Pustaka.
Sari, I. D. (2008) Manajemen Pemasaran Usaha Kesehatan. Yogyakarta: Mitra Cendekia.

Supranto, J. (2006) Pengukuran Tingkat Kepuasan Pelanggan untuk Menaikkan Pangsa Pasar. III. Jakarta: Rineke Cipta.

Tjiptono, F. (2008) Strategi Pemasaran. 3 ed. Yogyakarta: ANDI.

Ware, J., Devies-Avery, A. dan Stewart, A. (tanpa tanggal) "The Measurement and Meaning of Patient Satisfaction: a Review of the Literature 1977."

Ware, J. dan Snyder, M. (1975) "Dimensions of Patient Attitudes Regarding Doctors and Medical Care Services."

Wilson, A. et al. (2006) "Development and testing of a questionnaire to measure patient satisfaction with intermediate care," Quality and Safety in Health Care, 15(5), hal. 314-319. doi: 